\title{
Gesamtinhaltsverzeichnis des Bandes 71 [1989]
}

Wilhelm Backhaus (Bochum), Servi vincti . . . . . . . . . . . . . . . 321

Wilhelm Backhaus (Bochum), Zentrum als Peripherie? Sozioökonomische Betrachtungen zu Metropolen des 3. und 4. Jh. . . . . . . . . . . . .

Юрий С. БАдальянц (Рязань), Вопросы хронологической класеификации Родосских керамических клейм . . . . . . . . . . . . . . . . . .

ERnst Badian (Cambridge, Mass.), The scribae of the Roman Republic . . . Joś Maria Blázquez (Madrid), Arte (mosaicos), sociedad e historia en la Hispania Romana del Alto Duero (s. IV) . . . . . . . . . . . . . . .

IRIS v. BREDOw (Sofia), Der qasireu in der Gesellschaftsstruktur des pylischen Staates . . . . . . . . . . . . . . . . . . . 28

Jan Burian (Prag) s. Pavel Oliva . . . . . . . . . . . . . . . . 477

Vhlia Chuaqui de Reimer (Leipzig) s. Hubert Reimer . . . . . . . . . 508

Lellia Cracco Ruggini (Turin), Juridical Status and Historical Role of Women in Roman Patriarchal Society . . . . . . . . . . . . . . . . Hans Ditten (Berlin), Zu Fragen des Siedlungsgebietes der Slawen in der Antike (1.-6. Jh.) nach den schriftlichen Quellen . . . . . . . . . . . 202

MASAOKI DOI (Kawasaki), Bagaudes Movement and German Invasion . . . . 344

RAMTro Donciu (Azuga), Le règne de Gaius considéré comme „plaque tournante" dans l'histoire de l'Empire Romain . . . . . . . . . . . . . .

EndRe FERenczy (Budapest), Uber die Quellen der historischen Werke Varros unter besonderer Berücksichtigung der Antiquitates rerum humanarum .

Gonzalo Fernandez (Madrid), The Evangelizing Mission of Theophilus „The Indian" and the Ecclesiastical Policy of Constantius II . . . . . . . . 361

Pia de Frdio (Neapel), L'artigianato del bronzo nei testi micenei de Pilo . . . .

Hagen Fischer (Berlin), Fragen der Beziehungen zwischen Rom und Parthien und ihre Widerspiegelung in der damaligen Literatur (Mitte des 1. Jh. v. u. Z. bis Mitte des 1. Jh. u. Z.) . . . . . . . . . . . . . . . . . .

Lrviu Franga (Bukarest), Gabranus. Paläobalkanische onomastische Konkordanzen . . . . . . . . . . . . . . . . . . . . .

Diana Gragova (Sofia), The Find from Rogozen and one Religious Feast in the Thracian Lands

GotTFrIED HärteL (Leipzig), Bemerkungen zur Religionspolitik Konstantins I. . . . . . . . . . . . . . . . . . . . . . . . . . . . . . .

Miltiades B. Hatzopoulos (Athen), Grecs et barbares dans les cités de l'arrière-pays de la Chalcidique . . . . . . . . . . . . . . . . . . . 60

Nobuo Hayashr (Tokyo), Die pecunia in der pollicitatio ob honorem . . . . . 383

Joachim Herrmann - Reimar Müller (Berlin), Vorwort . . . . . . . . . 5

Walter Hofmann (Leipzig), Plautinisches in Plautus' Persa . . . . . . . . 399

Johannes Irmscher (Berlin), Die Geschichte des frühen Christentums als Bestandteil der Altertumswissenschaft . . . . . . . . . . . . . . . 408

Eszter Istvánovitz (Budapest) s. Andrea H. VAdAY . . . . . . . . . . . 107 
Wolfang $\mathrm{J}_{\text {AHN }}$ (Leipzig), Felicitas est secuta Italiam: Bemerkungen zur Lage der römischen Bevölkerung im 6. Jahrhundert in Italien . . . . . . . .

NikolaJ Jefremov (Greifswald), Einige vergessene Keramikstempel von Sinope aus dem Mittelmeerraum . . . . . . . . . . . . . . . . .

Helmut Kalex (Leipzig), Uberlegungen zu den Wirtschaftsbeziehungen zwischen römischer Provinz und Barbaricum an der mittleren Donau . .

Zsolt KIss (Warschau), Représentations de barbares dans l'iconographie Romaine impériale en Egypte . . . . . . . . . . . . . . . . . 127

Ernst Kluwe (Jena), Polisideologie und Handwerk . . . . . . . . . . . 414

JERzY Kolendo (Warschau), Les recherches sur l'esclavage au début du XVIII siècle (à propos du livre de F. Bianchini, Camera ed inscrizioni sepulcrali de Liberti, Servi, ed Ufficiali della Casa di Augusto Scoperte nella Via Appia, Rome 1727) . . . . . . . . . . . . . . . . . . . . . .

Barbara KüHnert (Jena), Populus Romanus und sentina urbis: zur Terminologie der plebs urbana der späten Republik bei Cicero . . . . . . . . 432

VAléria Kulcsár (Budapest) s. Andrea H. VAday _. . . . . . . . . . 107

HansulRich LabUSke (Berlin), Die Römer am Kimbernkap . . . . . . . . 138

Mark Lehrer (Denver), Die aufschlußreichen Mängel von Heinrich Schliemanns Selbstbiographie . . . . . . . . . . . . . . . .

Barbara Lichocka (Warschau), Le barbare dans les représentations de Némésis en l'Egypte Romaine . . . . . . . . . . . . . . . . . . . .

Barnabás Lőrincs (Budapest), Zu den Verbindungen zwischen Pannonien und Barbaricum: die Verbreitung und Datierung der Ziegelstempel . . . . .

Louisa Loukopoulou (Athen), Colons et indigènes dans la Thrace Propontique . . . . . . . . . . . . . . . . . . .

Allan A. Lund (München), Zu den Suebenbegriffen in der taciteischen Germania . . . . . . . . . . . . . . . . . . . . 620

Konstantin A. Marǒenko (Leningrad) s. JuriJ A. Vinogradov . . . . . . 539

Egon Maróti (Szeged), Zum Scheitern des ersten Übersetzversuches des Spartacus nach Sizilien . . . . . . . . . . . . . . . . .

Karl Matthiae (Berlin), Die Fassade von Ed-Der in Petra. Ein Beitrag zur nabatäischen Felsarchitektur . . . . . . . . . . . . . . . . 257

RICHARD A. McNeal (Evanston, Illinois), Rosén's Herodotus . . . . . . . . 555

Dieter Metzler (Münster), Uber das Konzept der „Vier großen Königreiche“ in Manis Kephalaia (cap. 77) . . . . . . . . . . . . . . . . . . . .

Frank Morgenstern (Berlin), Die Auswertung des opus agriculturae des Palladius zu einigen Fragen der spätantiken Wirtschaftsgeschichte . . .

REIMAR Müller (Berlin), Cicero und die Rezeption griechischer Gesellschaftstheorie in Rom . . . . . . . . . . . . . . . . . . . . . . . 460

Retmar Müller (Berlin) s. Joachim Herrmann . . . . . . . . . . . . . 5

Marlene NJammasch (Berlin), Gab es eine indische „Spätantike“? . . . . . 469

Pavel Oliva - Jan Burian (Prag), Die Prager Altertumswissenschaft und soziale Probleme der Antike. Die Entwicklungstendenzen in der Zwischen- und Nachkriegszeit . . . . . . . . . . . . . . . . . . . . .

Юрий В. Откупщиков (Ленинград), Карийский и греческий явык. Генетические и әтно-культурные отношения . . . . . . . . . . . . . . . 66

Patrick Pḱrin (Rouen), Paris mérovingien, sedes regia . . . . . . . . . . 487 
Holare Preissler (Leipzig), Altsyrische heidnische Namen in der frühen syrischen Literatur . . . . . . . . . . . . . . . . . . . . .

Hubert Reimer - Velia Chuaqui de Remmer (Leipzig), Priszillian und der Priszillianismus in den Akten spanischer Konzilien des 4. bis 6. Jahrhunderts . . . . . . . . . . . . . . . . . . . . . . .

ILSE RochOw (Berlin), Prosopographisches zu den Kaisern Leo III. und Konstantin V. . . . . . . . . . . . . . . . . . . . .

Arnold Roggisch (Berlin), Zur Geschichte des Räderpflugs in der römischgermanischen Synthesezone im Spiegel der lateinischsprachigen Schriftquellen. . . . . . . . . . . . . . . . . . . . . . . . . . .

Федор В. Шелов-Коведяев (Москва), Еще рав о государстве Синдов . . .

EdITh Schönert-Geiss (Berlin), Das Eindringen römischen Geldes auf den Balkan im 2./1. Jahrhundert v. u. Z. . . . . . . . . . . . . . . . .

Борис П. Селецкий (Ленинград), $\mathrm{K}$ вопросу о римских политических партиях . . . . . . . . . . . . . . . . . . . . . . . .

Alatn Silberman (Åbo), Le premier ouvrage latin de géographie: la Chorographie de Pomponius Méla et ses sources grecques . . . . . . . . . .

Thomas Sternberg (Rostock), Die Regierungszeit Gordians III. aus der Sicht der kaiserlichen Rechtsprechung . . . . . . . . . . . . . . . . .

George J. SzemLer (Chicago, Illinois), „The Pass through Trachis“ - Her. 7, 176, 2 . . . . . . . . . . . . . . . . . . . . . . . . .

ANGELIKA TRäGER (Leipzig), Ein Vergleich von spätantiker und frühfränkischer städtischer Besiedlung in Nordgallien . . . . . . . . . . . . .

Andrea H. Vaday - Eszter Istvánovits - Valéria Kulcsár (Budapest), Sarmatian Costume in the Carpathian Basin . . . . . . . . . . . . .

Mrhafr VASILESOU (Bukarest), Hellènes et barbares dans les épopées homériques . . . . . . . . . . . . . . . . . . . .

Veltzar Velkov (Sofia), Wulfila und die Gothi minores in Moesien . . . . .

JuriJ A. Vinogradov - Konstantin K. MarČenko (Leningrad), Das nördliche Schwarzmeergebiet in der skythischen Epoche. Periodisierung der Geschichte . . . . . . . . . . . . . . . . . . .

INGOMAR WeILER (Graz), Fremde als stigmatisierte Randgruppe in Gesellschaftssystemen der Alten Welt . . . . . . . . . . . . . . . . . .

JÜRGEN WERnER (Leipzig), Keine „individuelle Geschlechtsliebe“ in der Antike? . . . . . . . . . . . . . . . . . . . . .

Rezensionen - Annotationen

Wolfram Brandes (Berlin): Armies and Frontiers in Roman and Byzantine Anatolia . . . . . . . . . . . . . . . . . . . . . . . 304

JANA KePartová (Prag): Supplementa Italica n. s. 3 . . . . . . . . . . . . 309

Antony E. Raubitschek (Palo Alto, California): Kultur und Fortschritt in der Blütezeit der griechischen Polis, hrsg. von Ernst Kluwe . . . . . . Edith Schönert-Geiss (Berlin): BNF - Berliner Numismatische Forschungen 1 . . . . . . . . . . . . . . . . . . . . . . . . . 310

Edith Schönert-Gerss (Berlin): Fiorenzo Catalli, Le monete . . . . . . . 311 
Alatn Silberman ( $\AA$ \&oo): Claude Nicolet, L'inventaire du Monde. Géographie et politique aux origines de l'Empire Romain . . . . . . . . . . 306

Alatn Sllberman (Åbo): O. A. W. Dilke, Greek and Roman Maps . . . . . 307 HeIkKI Solin (Helsinki): Überlegungen zu den Halterner Graffiti. Brigitte Galsterer, Die Graffiti auf der römischen Gefäßkeramik aus Haltern . . . 290 Friedhelm Winkelmann (Berlin): Augustinus-Lexikon, hrsg. von Cornelius Mayer . . . . . . . . . . . . . . . 303

Friedhelm Winkelmann (Berlin): Georg Schöllgen, Ecclesia sordida? Zur Frage der sozialen Schichtung frühchristlicher Gemeinden am Beispiel Karthagos zur Zeit Tertullians . . . . . . . . . . . . . . . . . 301 